\title{
Discriminative control of interspecific killing in hungry and satiated rats
}

\author{
ISRAEL POSNER and WILLIAM M. MILEY \\ Richard Stockton State College, Pomona, New Jersey
}

\begin{abstract}
Hungry and satiated killer Long-Evans rats were exposed to two species of prey, mice and frogs. Experiment 1 demonstrated that the rats learned to discriminate between prey when attacks upon one of the prey were punished by electric shocks and attacks upon the alternative were not punished. Thus, killing of the "dangerous" prey was suppressed, while killing of the alternative, "safe" prey continued. However, in Experiment 2-in which the consequences of killing the prey differed in that one was allowed to be eaten following a kill but the other was not-no evidence of discriminative attack resulted. Hungry and satiated rats did not differ in their responsiveness toward prey as objects of attack, but hungry killers were more responsive to prey as food, thus demonstrating a dissociation of killing and eating control.
\end{abstract}

In their natural habitats, predators frequently have more than one species of potential prey available to them. The predator's chances of survival may depend on its ability to discriminate between potentially dangerous and safe, nutritious prey. For example, predator birds will inhibit attacks on poisonous prey like the monarch butterfly while they continue to sustain themselves by preying on more innocuous species (Brower \& Brower, 1964). The general issue with which these experiments concern themselves is: Are there reinforcement contingencies that affect the killer rat's choice of victims? In the first experiment, the killer rat's relative aggressiveness toward mice and frogs was tested under conditions in which attacks upon one of these prey were made experimentally noxious to the rat.

Some laboratory rats will kill mice and frogs as well as a variety of other small animals with a stereotypic attack that is usually directed toward the victim's dorsal surface in the neck region (Bandler \& Moyer, 1970; Karli, 1956). A variety of experimental manipulations affect the probability of killing within a group of rats. Among the variables that increase the frequency of mouse killing, for example, is food deprivation (Paul, Miley, \& Baenninger, 1971). Although Karli (1956) and Heimstra (1965) reported that food-deprived rats often starved to death rather than kill mice continuously left in their cages, their failure to kill was probably due to the interfering ef-

This research was submitted in partial fulfilment of the requirements for the $\mathrm{PhD}$ degree at Temple University. The first author wishes to express his appreciation to Ronald Baenninger for his helpful criticism. Requests for reprints should be sent to Israel Posner, Psychology Program, Richard Stockton State College, Pomona, New Jersey 08240. fects of long-term familiarization with mice (Paul, 1972). Indeed, without familiarization during the deprivation period, Paul et al. (1971) and Whalen and Fehr (1964) found that deprived rats were much more likely to kill mice than were satiated rats.

Furthermore, although food deprivation increases the probability of killing in naive rats, being hungry is not necessary for the maintenance of the killing response. In fact, Paul et al. (1971) found that virtually all rats that killed while food deprived continued to kill mice when subsequently tested while satiated.

The killing response of the rat is also susceptible to inhibitory environmental control. For example, an extensive series of experiments by Myer and Baenninger (Baenninger, 1970; Myer, 1966, 1967, 1968; Myer \& Baenninger, 1966) showed that the rat's killing response can be temporarily suppressed with responsecontingent shock. Shocks uncorrelated with attacks did not suppress killing (Myer, 1968).

The present series of experiments sought to extend knowledge of suppression of killing by examining the presence or absence of target specificity. Furthermore, we looked at its interaction with the state of food deprivation or satiation. Specifically, the first experiment was designed to answer two questions: (1) Are the suppressive effects of punishment specific to the prey upon which attacks are punished (i.e., do "safe" prey continue to be attacked)? Or, alternatively, (2) does suppression of killing generalize such that attacks upon "safe" prey are also inhibited? The second question concerns the possible interaction between the potentiating effects of food deprivation and the inhibitory effects of punishment. The answer to these questions on mouse-killing could shed some light on how environmental contingencies control consummatory behavior in general. 


\section{EXPERIMENT 1}

\section{Method}

Subjects. In the first experiment, 20 reliable killer Long-Evans rats (males, $200-250 \mathrm{~g}$ ) were selected randomly from a pool of rats that had undergone a series of preexperimental killing tests.

Apparatus and Procedures. Three phases of selection tests were given in order to obtain a pool of highly reliable killer rats. Phase 1 (home-cage, deprived) testing took place in the rats' home cages (individually housed, wire mesh) following 8 days of 23-h cyclic food deprivation. Six 30-min tests were given over a 3-day period, three with mice as prey (adult, male and female albinos) and three with frogs (2-in. Rana pipiens) as prey. In all tests, dead prey were immediately confiscated after a kill to prevent them from being eaten by the rat.

Phase 2 (home-cage, satiated) tests took place following 4 days of ad-lib feeding. Those rats that killed in all Phase 1 tests were given one mouse and one frog test in their home cages.

Phase 3 (shock-box, satiated) tests took place in the shock boxes wherein subjects remained for the duration of the experiment. As before, one mouse and one frog test were administered to cull out those rats that would not kill in the novel environment.

The shock boxes were electrifiable and measured $8.25 \times 7 \times$ $6.5 \mathrm{in}$. Two sides were metal, and the other two sides and top were Plexiglas. The floor consisted of steel rods $3 / 32$ in. in diameter and spaced $1 / 2$ in. apart. Electric shock was delivered to each box from a Lehigh Valley (No. 1424) shocker that delivered approximately $1.5 \mathrm{~mA}$ at the grids. The shock boxes were located in a ventilated room that was maintained on a 24 -h reverse day/night cycle. All testing took place during the "night" phase of the cycle, during which the only available light sources were a small number of $60-\mathrm{W}$ bulbs suspended a few feet over the shock boxes.

Following selection phases, discriminative punishment training and recovery from punishment were then instituted. During discriminative punishment, only those rats that had killed in all the preexperimental tests were included in the experimental part of the study and data analysis. Beginning on the fourth day following the shock-box satiated tests, 20 subjects were assigned randomly to one of four groups (five subjects per group). Subjects were either on 23-h cyclic food deprivation or on ad-lib feeding, and either mouse or frog attacks were punished. Attacks on the alternative prey were "safe." Thus, the design was a $2 \times 2$ factorial. Each subject was alternatively presented with mice and frogs at approximately 30 -min intertrial intervals. Two trials with each type of prey were given on each day for 4 consecutive days. Thus, there was a total of 16 trials, eight with mice and eight with frogs.

Depending upon group, attacks on one type of prey were followed by immediate footshock. Shock termination was contingent upon cessation of the attack. On the intervening trials with the alternative prey ("'safe"), no shocks were ever given. On all trials, if a kill occurred, the dead prey were immediately removed. If on a particular trial an attack did not occur within $5 \mathrm{~min}$, the prey was removed and the trial terminated. Experience in our lab indicates that experienced killers will generally kill in considerably less than $5 \mathrm{~min}$ if they are going to kill at all.

On the day following the last discriminative punishment trial, recovery trials began. In this phase, subjects were given one mouse
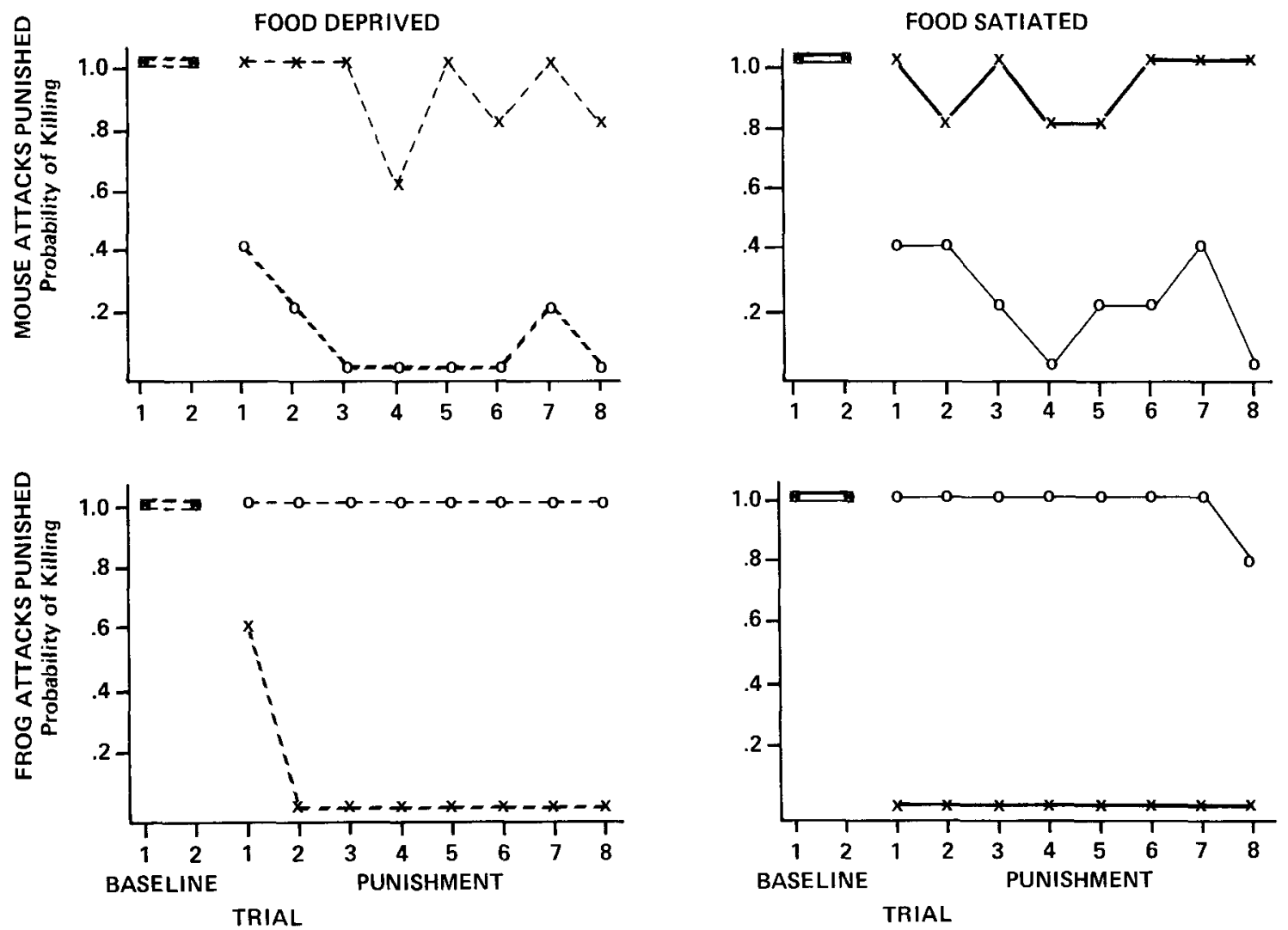

Figure 1. Percentage of subjects killing "dangerous" and "safe" prey during discriminative punishment phase (N=5/group). 


$$
\begin{array}{ll}
a-0 & \text { SATIATED, MOUSE - PUNISHED } \\
0---0 & \text { DEPRIVED, MOUSE - PUNISHED } \\
\hdashline-\star & \text { SATIATED, FROG - PUNISHED } \\
\star--\star & \text { DEPRIVED, FROG - PUNISHED }
\end{array}
$$

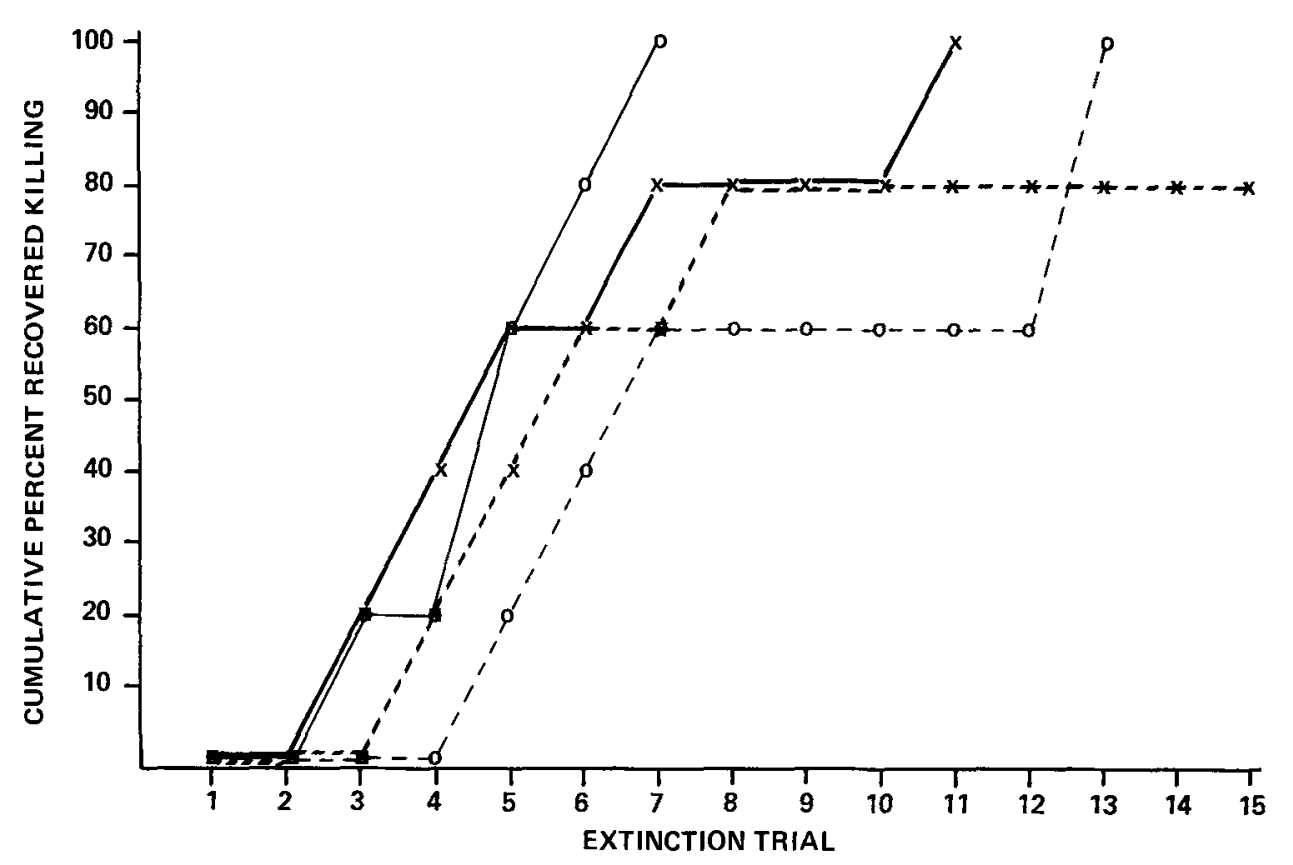

Figure 2. Cumulative percentage of subjects that reached the recovery criterion during extinction trials $(\mathrm{N}=5$ / group).

and one frog test per day without any shocks at all. Trials were continued on a daily basis for the first 10 days and thereafter every fifth day until Day 30 or until subjects recovered killing the previously "dangerous" prey on two successive tests.

\section{Results and Discussion}

During the experimental phases, all subjects in all four groups learned to discriminate between "dangerous" and "safe" prey (sign tests, ps $<.05$ ). As Figure 1 shows, in all groups, killing of the dangerous prey was immediately and drastically suppressed, while killing of "safe" prey continued at baseline levels. Whether subjects were food deprived or satiated did not affect the number of subjects that killed "dangerous" and "safe" prey $\left[\chi^{2}(1)=1.02, \mathrm{p}>.05\right]$.

The recovery data indicated that the effects of discriminative punishment training were temporary; as Figure 2 shows, virtually all rats recovered killing the previously dangerous prey by Trial 13. There were no significant differences among the groups in recovery rate. This finding is consistent with the temporary suppressive effects of shock reported by Myer (1966).

\section{EXPERIMENT 2}

Since, in Experiment 1, there was little, if any, generalization of suppression to the "safe" prey, it seemed clear that attack-contingent aversive stimulation does not generally suppress attack behavior, but is rather specific in its action. The lack of a general suppression of attack behavior has obvious adaptive significance in that it ensures the predator's continued attacks on other types of prey. Therefore, while Experiment 1 established that an aversive contingency is sufficient to induce discriminative attack behavior, Experiment 2 sought to determine whether the opportunity to engage in a consummatory behavior like feeding could produce discriminative attack behavior such as the aversive contingency did.

\section{Method}

Subjects. The 20 subjects for this experiment were drawn randomly from the pool of killers that had undergone the preexperimental testing described earlier.

Procedure. The experimental procedures of Experiment 1 were replicated; however, this time no shocks were administered. In- 
stead, the consequences of attacking the two types of prey differed in that killing of one was followed by the opportunity to feed on the victim for 15 min following the kill ("ingestible" prey), while feeding was not permitted following a kill of the alternative ("noningestible') prey. Thus, as in Experiment 1, a $2 \times 2$ factorial design was employed (five subjects per group). Subjects were either on restricted feeding schedules or on ad-lib feeding, and, depending upon group, either mice or frogs served as the "ingestible" prey.

\section{Results and Discussion}

Whether or not subjects had the opportunity to eat the prey after a kill did not affect the likelihood of the prey's being attacked and killed. In other words, "ingestible" as well as "noningestible" prey were attacked and killed virtually $100 \%$ of the time by deprived as well as by satiated subjects.

In marked contrast killing, the latencies to begin eating the ingestible prey following a kill were significantly shorter (Mann-Whitney $U=26, z=3.85$, $\mathrm{p}<.001$ ) for the deprived (median $=63 \mathrm{sec}$ ) than for the satiated (median $=121 \mathrm{sec}$ ) groups. Thus, food deprivation seems to enhance the responsiveness of killer rats to mice as food. But, the probability of killing, which is at very high levels in these subjects, is not apparently diminished by satiety.

\section{GENERAL DISCUSSION}

The differential effects of food deprivation on killing strength and eating latencies support Paul's (1972) contention that the mechanisms controlling eating and killing motivation can be separated. Previous work (Paul \& Posner, 1973) has shown that, although mouse-killing rats do, indeed, tend to eat their victims following a kill, there was no evidence that the act of killing per se increases the likelihood or strength of subsequent eating. In other words, killer rats were as likely to eat mice following a kill as they were at times when they had not just killed.

Further evidence of a dissociation of killing and eating mechanisms comes from work by Paxinos (1973), who found evidence of a neuroanatomical separation of eating and killing circuits. In addition, Berg and Baenninger (1974) found that mouse-killing rats would stop eating mice after lithium-chloride poisoning but would not stop killing them, and Myer and Baenninger (1966) found that punishment of killing effectively stopped the killing but did not stop occasional eating of mouse carcasses.

In conclusion, it appears that (1) the killer rat's relative aggressive responsiveness toward two other species (i.e., as available objects of attack) can be more easily manipulated by aversive consequences rather than appetitive ones, (2) the suppressive effects of the aversive contingency on killing one species do not seem to generalize to the killing of another species, and (3) although the latency of the killer rat's aggressive responsiveness toward mice and frogs is not a function of deprivation condition, its responsiveness toward them as food is a function of food deprivation. The last conclusion follows from Baenninger's (1978) observation that "rats are discriminating about what they feed on, and less discriminating about what they kill."

\section{REFERENCES}

BaEnNinger, R. Suppression of interspecies aggression in the rat by several aversive training procedures. Journal of Comparative and Physiological Psychology, 1970, 70, 382-388.

Batnninger, R. Some aspects of predatory behavior. Aggressive Behavior, 1978, 4, 287-311.

Bandler, R., \& MoYer, K. E. Animals spontaneously attacked by rats. Communications in Behavioral Biology, 1970, 5, 177-182.

Berg, D. S., \& Baenninger, R. Predation: Separation of aggressive and hunger motivation by conditioned aversion. Journal of Comparative and Physiological Psychology, 1974, 86, 601-605.

Brower, L. P., \& Brower, J. V. Birds, butterflies, and plant poisons: A study in ecological chemistry. Zoologica, 1964, 49, 137-159.

Heimstra, N. W. A further investigation of the development of mouse-killing in rats. Psychonomic Science, 1965, 2, 179-180.

KarL1, P. Norway rat's killing response to the white mouse: An experimental analysis. Behaviour, 1956, 10, 81-103.

Mye R, J. S. Punishment of instinctive behavior: Suppression of mouse-killing by rats. Psychonomic Science, 1966, 4, 385-386.

Myer, J. S. Prior killing experience and the suppressive effects of punishment on the killing of mice by rats. Animal Behaviour, $1967,15,59-61$.

MYER, J.S. Associative and temporal determinants of facilitation and inhibition of attack by pain. Journal of Comparative and Physiological Psychology, 1968, 66, 17-21.

Myer, J.S., \& Baenninger, R. Some effects of punishment and stress on mouse killing by rats. Journal of Comparative and Physiological Psychology, 1966, 62, 292-297.

Paul, L. Predatory attack by rats: Its relationship to feeding and type of prey. Journal of Comparative and Physiological Psychology, 1972, 78, 69-76.

Paul, L., Miley, W., \& Baenninger, R. Mouse killing by rats: Roles of hunger and thirst in its initiation and maintenance. Journal of Comparative and Physiological Psychology, 1971, 76, 242-249.

Paut, L., \& Posner, I. Predation and feeding: Comparisons of feeding behavior of killer and non killer rats. Journal of Comparative and Physiological Psychology, 1973, 84, 258-264.

Paxinos, G. Midbrain and motivated behavior. Journal of Comparative and Physiological Psychology, 1973, 85, 64-69.

Whalen, R. E., \& FEHR, H. The development of the mouse killing response in rats. Psychonomic Science, 1964, 1, 77-78.

(Manuscript received October 13, 1981; revision accepted for publication February 10, 1982.) 